\title{
ANATOMÍA REPRODUCTIVA EN FLORES ESTAMINADAS Y PISTILADAS DE Allophylus edulis (Sapindaceae)
}

\author{
VALERIA V. GONZÁLEZ ${ }^{1,2}$, STELLA M. SOLÍS2,3 y MARÍA S. FERRUCCI²
}

\begin{abstract}
Summary: Reproductive anatomy of staminate and pistillate flowers of Allophylus edulis (Sapindaceae). Sporogenesis and gametogenesis of staminate and pistillate flowers of Allophylus edulis (Sapindaceae) were studied. Young anthers are similar in both types of flowers, they share the basic type of antheral development; they consist of epidermis, endothecium, two middle layers and a secretory tapetum with binucleate cells. Microsporogenesis is normal, the division of pollen mother cells is simultaneous, and microspore tetrads are tetrahedral and decussate. The mature anther in staminate flowers presents epidermal cells thinned at stomio level, and endothecium cells with fibrillar thickenings. A single locule is formed in the theca by dissolution of the septum and pollen grains are two-celled when shed, these are triporate or tetraporate. The gynoecium is reduced to a tricarpelar, trilocular pistillode, with an ovule per locule. Ovule degeneration occurs before meiosis. The mature anthers of pistillate flowers differ anatomically from those of staminate flowers. The endothecium does not develop fibrillar thickenings, middle layers and tapetum generally are persisting, and the stomium is nonfunctional; anthers are indehiscent. The gynoecium in pistillate flowers, has a tricarpellary and trilocular ovary. Each locule contains an ovule hemianatropous, bitegmic and crassinucellate, with an obturator well developed, and the megagametophyte is of Polygonum type. Results are discussed in relation to the known to the family.
\end{abstract}

Key words: Allophylus edulis, Sapindaceae, sporogenesis, gametogenesis.

Resumen: Se estudió la esporogénesis y gametogénesis de flores estaminadas y pistiladas de Allophylus edulis (Sapindaceae). La anteras jóvenes son similares en ambos tipos de flores, comparten el tipo básico de desarrollo anteral; presentan epidermis, endotecio con células binucleadas, dos capas medias, y tapete de tipo secretor, con células binucleadas. La microsporogénesis es normal, la división de las células madres de las micrósporas es simultánea y las tétrades son tetraédricas y decusadas. La antera madura en flores estaminadas presenta células epidérmicas adelgazadas a nivel del estomio y el endotecio con engrosamientos fibrosos. Se aprecia un único lóculo por teca por disolución del septo y los granos de polen son liberados al estado 2-celular, éstos son triporados o tetraporados. El gineceo está reducido a un pistilodio tricarpelar, trilocular, con un óvulo por lóculo. El óvulo degenera antes de que ocurra la meiosis. La antera madura de las flores pistiladas difiere anatómicamente de la de las flores estaminadas. El endotecio no desarrolla engrosamientos fibrosos, las capas medias y el tapete persisten, y el estomio no es funcional; las anteras son indehiscentes. El gineceo de las flores pistiladas, presentan ovario tricarpelar y trilocular. Cada lóculo contiene un óvulo hemianátropo, bitegumentado y crasinucelado, con obturador desarrollado; el megagametófito es de tipo Polygonum. Se discuten los resultados obtenidos en relación a lo conocido para la familia.

Palabras clave: Allophylus edulis, Sapindaceae, esporogénesis, gametogénesis.

1 Becaria de Pregrado, Secretaría General de Ciencia y Técnica, Universidad Nacional del Nordeste. E-mail: valvangon_15@hotmail.com

${ }^{2}$ Instituto de Botánica del Nordeste (CONICET-UNNE), Facultad de Ciencias Agrarias, Sgto. Cabral 213, 3400 Corrientes, Argentina.

${ }^{3}$ Facultad de Ciencias Exactas, Naturales y Agrimensura (UNNE), Av. Libertad 5500, 3400 Corrientes, Argentina. 


\section{INTRODUCCIÓN}

Sapindaceae s.str. presenta una distribución cosmopolita, cuenta con 140 géneros y ca. 1800 especies, la mayoría de las cuales habitan en zonas tropicales y subtropicales. En Argentina se encuentran 16 géneros y 45 especies (Ferrucci, 1998). Radlkofer (1931-1934) consideró para la familia 14 tribus, de ellas sólo Paullinieae posee especies con hábito trepador, las restantes son arbóreas o arbustivas. Se trata en su mayoría de especies monoicas, raramente dioicas o polígamas.

Allophylus edulis (A. St.-Hil.) Niederl. pertenece a la tribu Thouinieae. Está incluida dentro de las especies arbustivas o arbóreas (Joly et al., 1980; Ferrucci, 1991, 1998). Es una especie monoica que se caracteriza por presentar el tipo de estructura floral dominante en la familia, flores estaminadas con gineceo reducido a un pistilodio y flores morfológicamente hermafroditas pero funcionalmente pistiladas, con estambres cuyas anteras producen polen estéril y son indehiscentes.

Aunque Sapindaceae es una familia diversa y de amplia distribución, las investigaciones embriológicas en general han sido enfocadas a un limitado número de especies. La mayoría de los trabajos disponibles incluyen especies asiáticas del género aquí estudiado (Mathur \& Gulati, 1980, 1989), además de las de otros géneros como Lepidopetalum B1. (Mathur \& Gulati, 1981), Filicium Thwaites ex Benth. \& Hook. f. (Gulati \& Mathur, 1977), Xerospermum Bl., Nephelium L., Pometia J. R. Forst. \& G. Forst. (Ha et al. 1988) y Cardiospermum L. (Kadry, 1946; Nair \& Joseph, 1960), en este último caso la especie estudiada es de distribución cosmopolita. Entre los trabajos embriológicos más recientes se cuenta con el de Cao et al. (2008), donde se discute la posición sistemática, a nivel de familia, de Handeliodendron bodinieri (H. Lév.) Rehder sobre la base de los caracteres embriológicos; el de Solís et al. (2010), autoras que interpretaron la microsporogénesis y la microgametogénesis en Cardiospermum grandiflorum Sw. y en Urvillea chacoensis Hunz. $\mathrm{y}$ el de Zini et al. (2012) quienes trabajaron en Melicoccus lepidopetalus Radlk., especie dioica.

El objetivo del presente estudio es analizar en ambos tipos de flores, pistiladas y estaminadas de $A$. edulis: 1) aspectos de la anatomía reproductiva como anatomía de antera, esporogénesis, gametogénesis y unidad polínica; y 2) comparar estos resultados con la información embriológica previamente conocida para la familia.

\section{Materiales y Métodos}

Botones de flores estaminadas y pistiladas en diferentes etapas de desarrollo se fijaron en FAA (formol-alcohol $70^{\circ}$-ácido acético; 90:5:5). El material testigo se encuentra depositado en el herbario del Instituto de Botánica del Nordeste (CTES), Argentina.

Para la elaboración de preparados permanentes, el material se deshidrató en una serie de deshidratantes histológicos y aclarantes-preimpregnantes de Biopur ${ }^{\circledR}$ (Gonzalez \& Cristóbal, 1997). La impregnación en parafina se realizó según la técnica de Johansen (1940), el material se colocó en una mezcla de partes iguales de alcohol butírico terciario y aceite de parafina en estufa a $60^{\circ}$ por 10 hs, seguido de dos cambios en parafina entre 10 y 12 hs cada uno. Para la inclusión se utilizó Histoplast $₫$ (Biopack, Buenos Aires, Argentina). Se realizaron cortes longitudinales y transversales seriados con micrótomo rotativo en espesores entre 10-12 $\mu \mathrm{m}$ y se tiñeron con safranina-azul de Astra (Luque et al. 1996) antes de montar con bálsamo de Canadá sintético (Biopur, Buenos Aires, Argentina).

Las observaciones, fotografías y dibujos se efectuaron con un microscopio estereoscópico Leica MZ6 y un microscopio óptico Leica DM LB2 ambos equipos con cámara clara y cámara digital.

Las muestras de polen se obtuvieron de ejemplares de herbario del Instituto de Botánica del Nordeste, Corrientes (CTES). El material se acetolizó según la técnica de Erdtman (1960), se montó en gelatina glicerinada y se depositó en la Palinoteca de la UNNE (PAL-CTES). Se estudió el polen de un ejemplar, muestreando flores estaminadas y pistiladas. La terminología adoptada fue básicamente la de Erdtman (1966), también se consultó Punt et al. (2007). Los parámetros eje polar (P) y eje ecuatorial (E) fueron medidos en la vista ecuatorial de 20 granos para cada una de las muestras. Para el análisis de la arquitectura de pared se utilizaron fotomicrografías obtenidas con un microscopio electrónico de barrido, JEOL $5800 \mathrm{LV}$ operando a $20 \mathrm{KV}$; se utilizaron granos acetolizados, metalizados con oro. 


\section{V. González et al. - Anatomía reproductiva en Allophylus edulis}

Material de estudio. Allophylus edulis: ARGENTINA. Prov. Corrientes. Dpto. Capital. Corrientes, 2.VIII.2008, Ferrucci \& Lezcano 2836 (CTES); Dpto. Gral. Paz. Ea. La Flecha, Lomas de Vallejos, 27.VIII.1979, Ferrucci et al. 152 (CTES); Dpto. San Martín. Ruta 40, ca. Desvío al Estero Cambá Trapo, $7 \mathrm{Km}$ E de Colonia Pellegrini, 15.IX.1999. Schinini et al. 35034 (CTES); Dpto. Santo Tomé. Garruchos, destacamento de Prefectura a orillas del río Uruguay, 6.IX.1993, Arbo et al. 5842 (CTES).

\section{Resultados}

\section{Morfología floral}

Las flores son zigomorfas, pequeñas y blanquecinas; de 2-4 $\mathrm{mm}$ de longitud. La flor estaminada posee 8 estambres exertos de $1.5-3 \mathrm{~mm}$ de longitud con anteras dehiscentes, y el gineceo reducido a un pistilodio. La flor pistilada presenta estambres más cortos, de $1 \mathrm{~mm}$ de longitud, con anteras indehiscentes; el gineceo 2-3 carpelar, estilo filiforme, estigma 2-3-fido.

\section{Microsporangio, microsporogénesis y} microgametogénesis

Caracteres comunes a ambos tipos de flores: Las anteras jóvenes son bitecas y tetrasporangiadas. En un estado temprano del desarrollo, se diferencian debajo de la epidermis las células arquesporiales, isodiamétricas, que se dividen periclinalmente para dar lugar a células parietales primarias hacia afuera, y células esporógenas hacia adentro. Estas últimas sufren nuevas divisiones periclinales que dan lugar a células esporógenas secundarias que posteriormente se diferencian en células madres de las microsporas (Fig. 1A). El desarrollo de la pared es de tipo básico (Davis, 1966), las capas parietales secundarias externas e internas se dividen periclinalmente, ambas solo se diferencian por su ubicación, luego forman el endotecio, dos capas medias y el tapete. En un estado más avanzado del desarrollo de la pared anteral, se reconocen estas cuatro capas: la epidermis que presenta células globosas con contenido citoplasmático de color rojizo posiblemente relacionado a sustancias tánicas, y pelos simples; el endotecio con células rectangulares, tangencialmente angostas y binucleadas; dos capas medias de células alargadas tangencialmente, y el tapete de tipo secretor, uniseriado, con células grandes binucleadas (Fig. 1B, C). La microsporogénesis es normal, las células esporógenas primarias sufren unas pocas divisiones para dar lugar a las células madres del polen, las cuales forman una pared especial de calosa que se deposita entre la plasmalema y la pared primaria (Fig. 1C). La división de las células madres de las micrósporas es simultánea y las tétrades que se forman son tetraédricas y decusadas (Fig. 1D). Posteriormente la calosa se degrada y las micrósporas son liberadas en el lóculo (Fig. 1E).

Flores estaminadas. Conforme los granos de polen van madurando, las células del endotecio se elongan radialmente y se comienzan a diferenciar engrosamientos fibrosos en las paredes; concomitantemente las dos capas medias y el tapete comienzan a degradarse (Fig. 1F). La pared de la antera madura muestra células epidérmicas con el diámetro radial reducido y el endotecio en su máxima expansión radial con marcados engrosamientos fibrosos en las paredes radiales y tangenciales internas; las capas medias y el tapete se han desintegrado. En la antesis, el septo que separa ambos lóculos de la teca también sufre degradación (Fig. 1G), las células epidérmicas se adelgazan a la altura del estomio, lugar donde posteriormente se produce la dehiscencia, y se liberan los granos de polen al estado bicelular (Fig. 1H).

Flores pistiladas. Luego de liberadas las micrósporas en el lóculo, el tapete se mantiene íntegro, las células del endotecio no se elongan radialmente y tampoco se diferencian engrosamientos fibrosos en las paredes radiales (Fig. 1I). En la antesis, el septo que separa ambos lóculos de la teca se conserva. Los granos de polen se observan colapsados con el citoplasma contraído en la parte final de su desarrollo (Fig. 1J). Las anteras maduras son indehiscentes. Las células epidérmicas se mantienen turgentes observándose más pequeñas a la altura del estomio. De esta manera, la pared de la antera madura consiste de una epidermis con células turgentes, el endotecio con células que no aumentan su tamaño ni desarrollan engrosamientos fibrosos, las capas medias adelgazadas pero aún visibles y un tapete conspicuo con células intactas (Fig. 1K). 
Bol. Soc. Argent. Bot. 49 (2) 2014
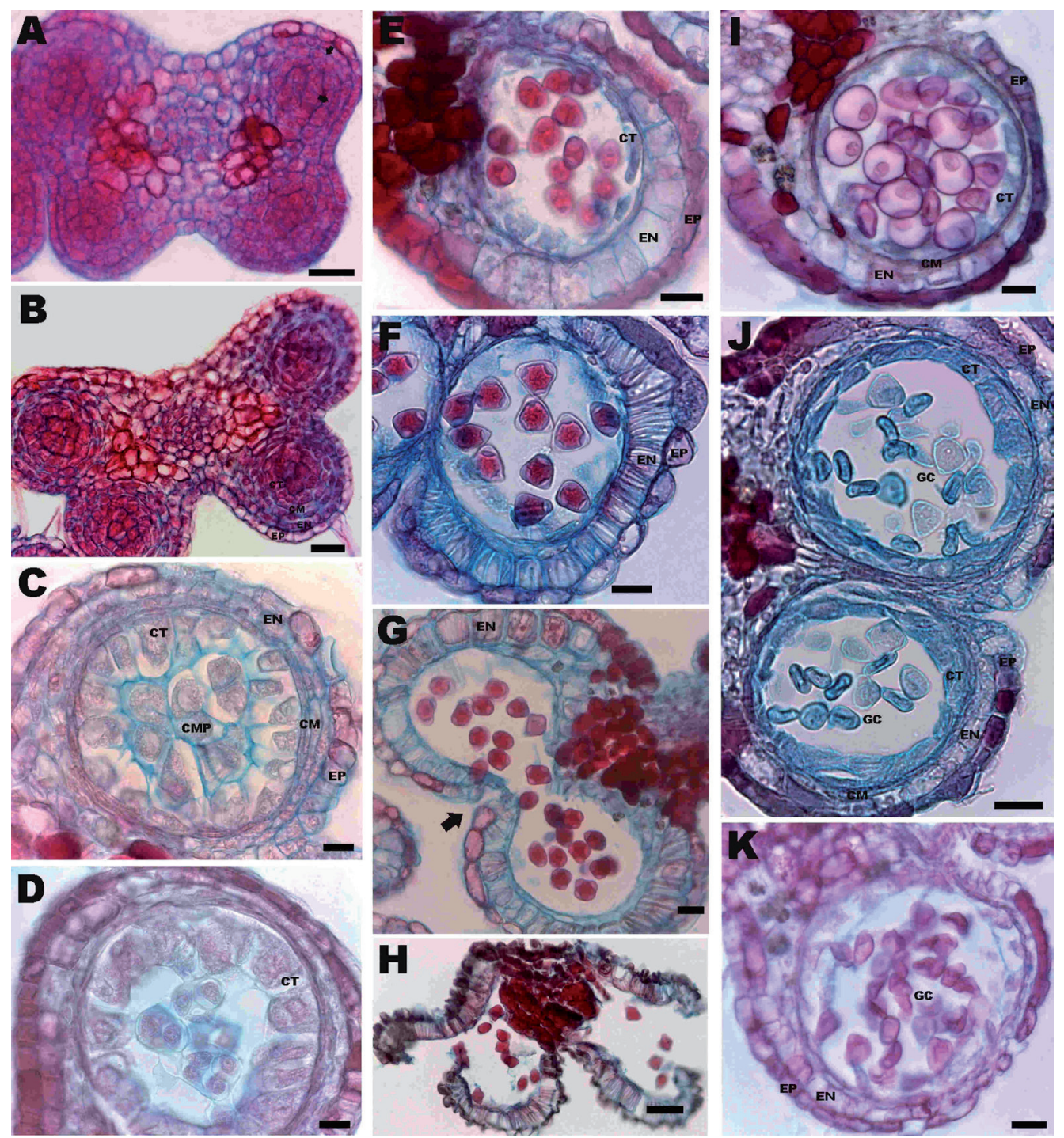

Fig. 1. Desarrollo de antera de flores estaminadas y pistiladas de $A$. edulis (cortes transversales en MO). A. Microsporangio joven con células esporógenas primarias y diferenciación de capas parietales (flechas muestran células en división). B. Antera donde se visualiza el tejido esporógeno y las capas de la pared. C. Antera con células madres del polen rodeadas por tapete, dos finas capas medias, endotecio delgado y la epidermis con células globosas. D. Antera con tétrades tetraédricas rodeadas de calosa. E-H. Flor estaminada: E. Antera con micrósporas libres; las células tapetales y las capas medias se observan parcialmente degradadas y el endotecio comienza a elongarse radialmente. F. Pared de antera con espesamientos radiales fibrosos en células del endotecio, reducción del septo que separa ambos esporangios y adelgazamiento de la capa epidérmica a la altura del estomio. G. Antera madura mostrando detalle de estomio (flecha). H. Antera dehiscente con granos de polen liberados. I-K. Flor pistilada: I. Antera con micrósporas libres; las células tapetales, las capas medias y el endotecio no muestran modificaciones. J. Antera en estadio maduro; el endotecio no desarrolla engrosamientos fibrilares; el septo que separa ambos lóculos se mantiene intacto (flecha), y los granos de polen presentan citoplasma contraído. K. Antera indehiscente con estomio no funcional en su máximo grado de maduración, granos de polen colapsados y tapete y capas medias parcialmente degradados. Abreviaturas: CM: células de la capa media, CMP: células madres del polen, CT: células tapetales, GC: granos colapsados,

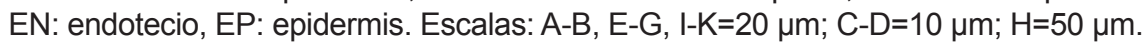


Megasporangio, megaspogénesis y megagametogénesis

Flores pistiladas. Cada carpelo presenta un óvulo hemianátropo, bitegumentado y crasinucelado, con un obturador desarrollado, que presenta una epidermis de células secretoras grandes, de aspecto globoso, alargadas radialmente y con un citoplasma denso y núcleo prominente (Fig. 3D). Los tegumentos se distinguen claramente durante la diferenciación de la megáspora funcional. El tegumento interno crece más que el externo, y sólo el primero delimita el micrópilo. El tegumento interno es multiestratificado y rodea a la nucela; está formado por 4-5 capas de células uninucleadas, pequeñas e isodiamétricas. El tegumento externo presenta el mismo número de capas de células; pero estas son más grandes y con núcleo conspicuo (Fig. 2A-C). A su vez, las células de la capa más externa son comparativamente más grandes y vacuoladas.

El desarrollo de la megasporogénesis y la megagametogénesis es normal. Una célula arquesporial subepidérmica se diferencia y se divide periclinalmente en dos. La superior sufre dos o tres divisiones mitóticas y se diferencian las células parietales (Fig. 3A). Luego, por sucesivas divisiones periclinales de la célula resultante superior, se originan entre 5 y 6 células parietales, mientras que la célula más interna funciona directamente como célula madre de las megásporas
(Fig. 3B). Esta célula tiene un citoplasma denso con pequeñas vacuolas y un núcleo prominente. La misma sufre división meiótica dando como resultado una tétrade lineal (Fig. 3C), de la cual degeneran las tres células superiores, quedando sólo la megáspora calazal viable. A partir de esta última, a través de tres cariocinesis mitóticas se origina un saco embrionario 8-nucleado, una vacuola central polariza cuatro núcleos hacia el extremo micropilar y cuatro hacia el calazal. Luego de producida la citocinesis, el megagametófito consiste de siete células: la ovocélula, dos sinérgidas, la célula central y tres antípodas (Fig. 3E). La ovocélula y las dos sinérgidas son células pequeñas que están ligeramente vacuoladas (Fig. 3F). La célula central es grande y de forma alargada, presenta una gran vacuola central y dos núcleos polares que se fusionan antes de la fertilización. Las antípodas son de tamaño reducido, presentan vacuolas muy pequeñas y núcleos conspicuos; son células efímeras que degeneran durante la maduración del gametofito femenino. En la nucela se observa la presencia de una epístasis constituida por células más grandes que el resto, con paredes más engrosadas, citoplasma denso y un núcleo conspicuo (Fig. 3F).

Flores estaminadas. Los óvulos, uno por lóculo, de inserción basal y de posición erecta, no se
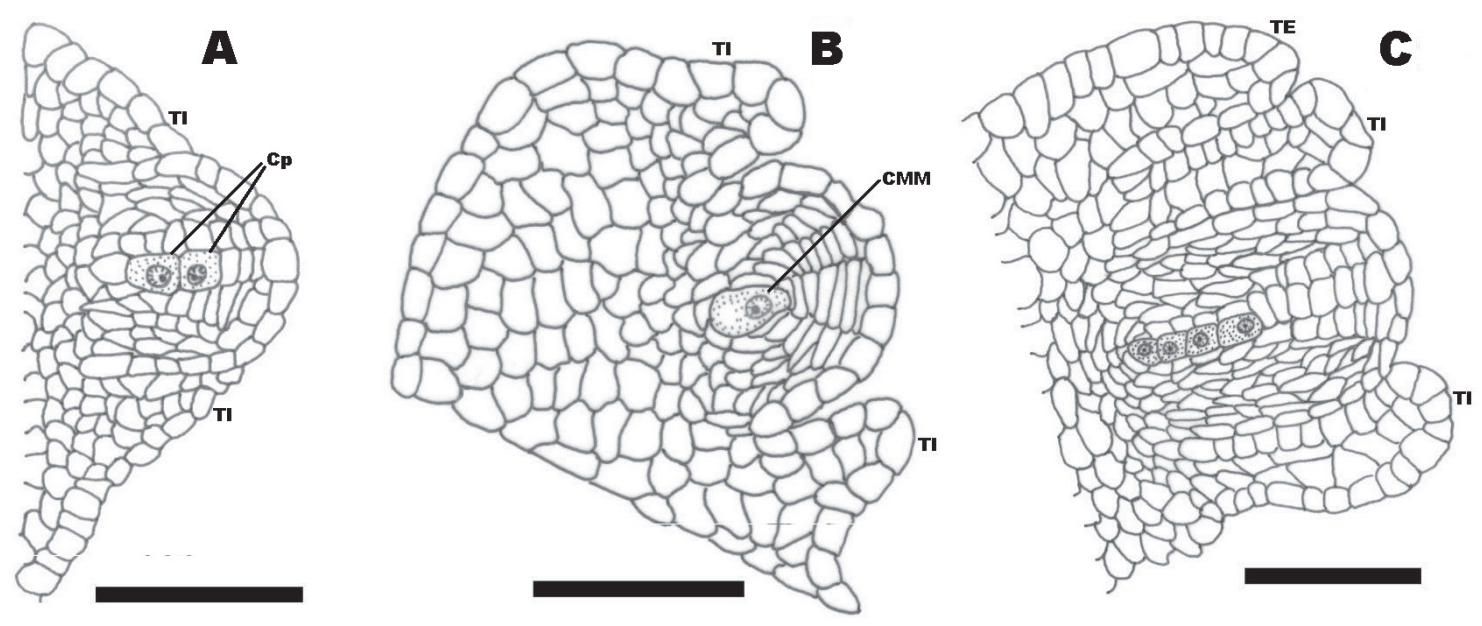

Fig. 2. A. Óvulo joven que muestra división de células parietales $(\mathrm{Cp})$ y diferenciación de tegumento interno (TI). B. Óvulo joven donde se observa la célula madre de la megáspora (CMM). C. Óvulo con tegumento interno (TI) y tegumento externo (TE) bien diferenciados, en la nucela se visualiza una tétrade lineal de megásporas. Escalas: $\mathrm{A}-\mathrm{C}=50 \mu \mathrm{m}$. 
Bol. Soc. Argent. Bot. 49 (2) 2014

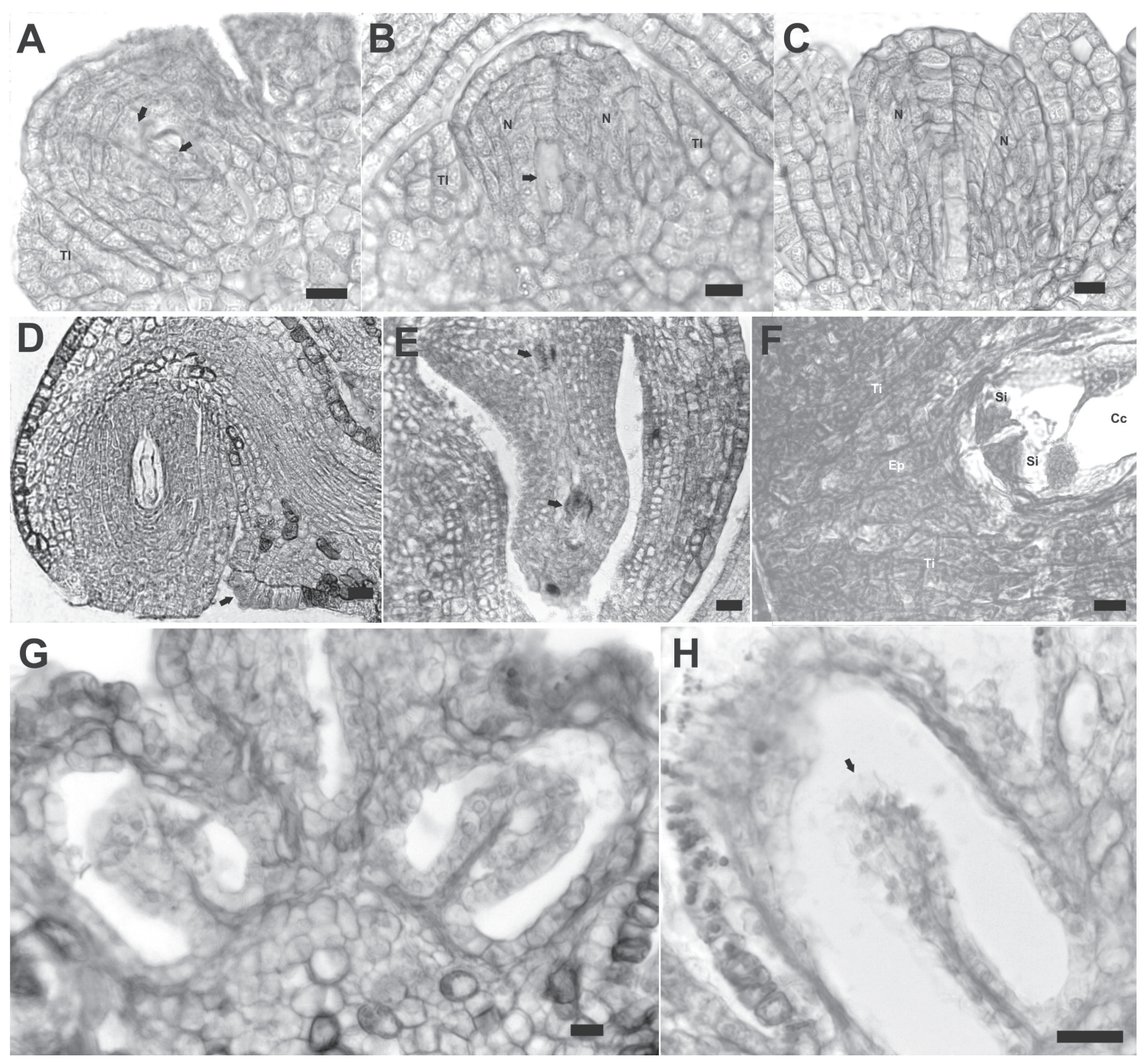

Fig. 3. Desarrollo del óvulo, megasporogénesis y megagametogénesis (cortes longitudinales en MO). A-F. Flor pistilada: A. Primordio de óvulo con dos células parietales (flechas). B. Óvulo con célula madre de la megáspora (flecha), se observa el primordio del tegumento interno. C. Detalle de tétrade lineal. D. Óvulo con saco embrionario inmaduro, se aprecian los tegumentos interno y externo, y obturador desarrollado (flecha). E. Gametofito femenino (flecha). F. Detalle del gametofito femenino, se observan las 2 sinérgidas con aparato filar, la ovocélula y dos núcleos de la célula central. G-H. Flor estaminada: G. pistilodio con óvulos atrofiados. H. Detalle del óvulo degenerado, se observan desintegración de células del tejido nucelar, y los tegumentos reabsorbidos (flecha). Abreviaturas: Ep: epístasis, Cc: célula central, N: nucela, $\mathrm{Si}$ : sinérgidas, TE: tegumento externo, TI: tegumento interno. Escalas: $\mathrm{A}-\mathrm{C}, \mathrm{G}=10 \mu \mathrm{m} ; \mathrm{D}-\mathrm{F}, \mathrm{H}=20 \mu \mathrm{m}$.

desarrollan completamente, degeneran antes de la diferenciación de la célula arquespórica, produciéndose una reducción del tejido nucelar debido a la desintegración de sus células, mientras paralelamente se reabsorben en forma gradual los tegumentos (Fig. $3 \mathrm{G} \mathrm{y} \mathrm{H}$ ).

\section{Granos de polen}

Los granos de polen de Allophylus edulis son triporados en un $79,5 \%$ y tetraporados en un $20,5 \%$, isopolares a subisopolares, radiosimétricos, de ámbito triangular y anguloaperturados. La sexina es microrreticulada (Fig. 4). 

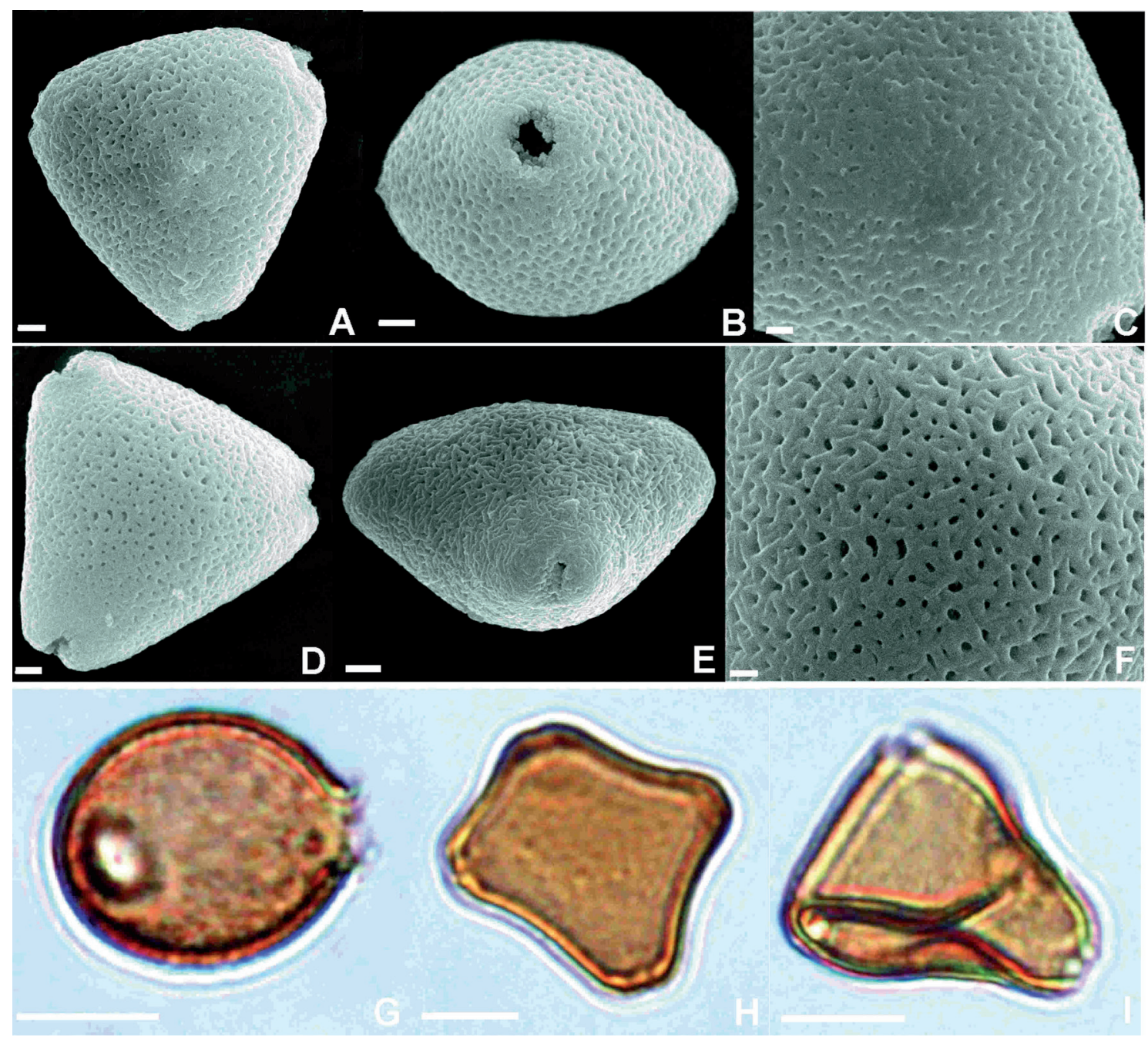

Fig. 4. Granos de polen. MEB: A-C, Flor estaminada. A. Vista polar. B. Vista ecuatorial. C. Detalle de escultura. D-F, Flor pistilada. D. Vista polar. E. Vista ecuatorial. F. Detalle de escultura. MO: G-H, Flor estaminada. G. Vista ecuatorial. H. Grano tetraporado en vista polar. I. Flor pistilada. Grano de polen

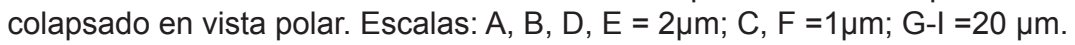

Se observaron diferencias en el polen maduro de ambos tipos de flores. En las flores estaminadas el $100 \%$ de las unidades polínicas son normales, sin evidenciarse granos colapsados (Fig. 4AC); mientras que en las anteras indehiscentes de las flores pistiladas se observó que las unidades polínicas se hallaban colapsadas, con su citoplasma contraído en un $54,8 \%$ de los casos, mientras que el 45,2\% restante de ellos aparentan ser normales (Fig. 4D-F). Por otra parte, en cuanto a las dimensiones de los granos de polen en cada tipo de flor, no se evidenciaron diferencias. En la Tabla
1 se resumen parte de los resultados obtenidos en el análisis polínico.

\section{Discusión}

Allophylus edulis presenta un tipo de estructura floral característico y dominante en la familia Sapindaceae. Se trata de flores funcionalmente unisexuales, aunque morfológicamente las flores estaminadas muestran un gineceo reducido a un pistilodio y las flores pistiladas presentan estambres 
Bol. Soc. Argent. Bot. 49 (2) 2014

Tabla 1. Características polínicas observadas en las flores estaminadas y pistiladas de $A$. edulis.

\begin{tabular}{|lcc|}
\hline \multicolumn{1}{|c}{ Características } & Flores estaminadas & Flores pistiladas \\
\hline Promedio de eje ecuatorial en $\mu \mathrm{m}$ & 24,5 & 24,7 \\
Promedio de eje polar en $\mu \mathrm{m}$ & 15,4 & 15,5 \\
Granos de polen normales & $100 \%$ & $42,2 \%$ \\
Granos de polen colapsados & -- & $54,8 \%$ \\
\hline
\end{tabular}

con anteras indehiscentes. En un estudio realizado en Handeliodendron bodinieri, Cao et al. (2008) definen a este patrón de dimorfismo sexual como "flores pseudo-bisexuales" (en apariencia bisexuales pero funcionalmente unisexuales). Las flores serían bisexuales en estadios muy tempranos del desarrollo.

La especie aquí estudiada, presenta en ambos tipos de flores un desarrollo de la pared de la antera que corresponde al tipo básico. Este fenómeno fue también observado en algunas especies de la familia como Cardiospermum grandiflorum, Urvillea chacoensis (Solís et al. 2010), y Handeliodendron bodinieri (Cao et al. 2008). No obstante, difiere de lo documentado para otras especies de Allophylus, como por ejemplo en $A$. zeylanicus L. y $A$. alnifolius (Baker) Radlk., como así también para Lepidopetalum jackianum Radlk. en las cuales se describió un desarrollo de pared anteral de tipo dicotiledóneo (Mathur \& Gulati, 1980, 1981, 1989).

En A. edulis ambos tipos de flores comparten características anatómicas en estados tempranos del desarrollo de la antera. Sin embargo, en estados más avanzados, las flores pistiladas evidencian diferencias anatómicas con respecto a las flores estaminadas. El endotecio, el tapete y los granos de polen siguen procesos distintos, llegando en última instancia a la obtención de unidades polínicas no funcionales en las flores pistiladas. Un patrón similar fue descripto para C. grandiflorum y $U$. chacoensis (Solís et al. 2010) y para Melicoccus lepidopetalus (Zini et al., 2012).

La presencia de células tapetales uninucleadas o binucleadas en $A$. edulis, es un carácter que comparte con M. lepidopetalus (Zini et al., 2012). Sin embargo, se trata de un aspecto variable dentro de la familia. En especies como $C$. grandiflorum, U. chacoensis (Solís et al., 2010) y H. bodinieri (Cao et al., 2008) las células tapetales son uninucleadas, mientras que en $A$. zeylanicus pueden llegar a ser trinucleadas (Mathur \& Gulati, 1989), en A. alnifolius varían desde uninucleadas a multinucleadas (Mathur \& Gulati, 1980), y en $L$. jackianum son multinucleadas (Mathur \& Gulati, 1981).

En el material aquí analizado, en las anteras maduras de flores estaminadas, el endotecio presenta engrosamientos fibrosos en las paredes radiales y tangenciales internas, carácter común con otras especies de la familia, dentro del mismo género A. zeylanicus y A. alnifolius (Mathur \& Gulati, 1980 y 1989), y en especies de otros géneros como L. jackianum (Mathur \& Gulati, 1981), C. grandiflorum, U. chacoensis (Solís et al., 2010) у M. lepidopetalus (Zini et al., 2012). Mientras que en las anteras de las flores pistiladas maduras de A. edulis, las células del endotecio no aumentan radialmente su tamaño y no desarrollan engrosamientos fibrosos en las paredes radiales, carácter que también fue observado en M. lepidopetalus (Zini et al., 2012). Sin embargo, difiere de lo observado en $C$. grandiflorum y $U$. chacoensis donde las células del endotecio evidenciaron elongación radial y desarrollaron engrosamientos fibrosos, aunque menos marcados que en las flores estaminadas (Solís et al., 2010). Por último, en Xanthoceras sorbifolium Bunge se describieron engrosamientos fibrosos de similar desarrollo en ambos tipos de flores (Zhou \& Liu, 2012), se señala que esta especie antes incluida en Sapindaceae fue transferida recientemente a la familia monotípica Xanthoceraceae (Buerki et al., 2010).

En las especies citadas las anteras de las flores pistiladas son siempre indehiscentes, las células del estomio no sufren degradación, y en la mayoría el septo que separa los esporangios permanece intacto. De esta manera, las unidades polínicas no son liberadas al exterior, en lugar de ello, gradualmente van colapsando y contrayendo su citoplasma hacia el final del desarrollo. Sin embargo, en $X$. sorbifolium un $5 \%$ de las anteras puede ser dehiscente; sin embargo, aunque los granos de 


\section{V. González et al. - Anatomía reproductiva en Allophylus edulis}

polen puedan germinar y producir tubos polínicos, no pueden fecundar con éxito a los óvulos (Zhou \& Liu, 2012).

En relación al desarrollo del megasporangio, se evidenció que en las flores funcionalmente pistiladas el proceso es normal, dando lugar a la formación de un megagametófito de tipo Polygonum, carácter que parece estar ampliamente distribuido en la familia (Mathur \& Gulati, 1980, 1981, 1989; Cao et al., 2008; Zhou \& Liu, 2012). Además, cada carpelo presenta un óvulo bitegumentado, crasinucelado, con obturador desarrollado que de acuerdo a la clasificación de Shamrov (1998) es de origen funicular. La presencia de obturador en Sapindaceae es un carácter que sólo comparte con algunas Rutaceae dentro del orden Sapindales (Weckerle \& Rutishauser, 2005).

Por otra parte, en las flores funcionalmente estaminadas el óvulo degenera antes de que ocurra la meiosis que daría lugar a la tétrade de megásporas. Simultáneamente, se produce la reducción del tejido nucelar debido a la desintegración de sus células y se reabsorben gradualmente los tegumentos. Este carácter no difiere de lo observado en $X$. sorbifolium en donde el pistilo aborta pronto luego de la formación del óvulo, incluso antes de que se produzca la formación de los tegumentos (Zhou \& Liu, 2012).

Por otra parte, en el estudio realizado se observó en las flores pistiladas el tipo de óvulo hemianátropo, carácter que comparte con A. alnifolius (Mathur \& Gulati, 1980), mientras que para A. zeylanicus se señala un tipo de óvulo anátropo (Mathur \& Gulati, 1989). Otro carácter interesante observado en $A$. edulis, es la ausencia de la hipóstasis citada como constante para los géneros de Sapindaceae (Corner, 1976), sin embargo entre las especies estudiadas este carácter es común con lo observado en Thinouia mucronata Radlk. (Solís, 2011). Se destaca que en la familia, la presencia de epístasis es compartida con C. grandiflorum Sw., Serjania meridionalis Cambess., Houssayanthus incanus (Radlk.) Ferrucci, Paullinia elegans Cambess., U. chacoensis Hunz. y T. mucronata (Solís, 2011).

El presente estudio suplementa la información embriológica disponible sobre SapindaceaeThouinieae, y aporta nuevas evidencias morfológicas, las cuales constituyen un aporte más para la discusión de las relaciones filogenéticas con Paullinieae, la tribu más afín.

\section{Agradecimientos}

Agradecemos a la Lic. Melisa Zini su asistencia en la preparación de las muestras de polen. Este trabajo fue financiado por la Agencia Nacional de Promoción Científica, Tecnológica y de Innovación (ANPCyT-UNNE, PICTO 2011-0202) y por la Universidad Nacional del Nordeste (PI A005-2009).

\section{Bibliografia}

BUERKI, S., LOWRY II P. P., ALVAREZ, N., RAZAFIMANDIMBISON, S. G., KÜPFER, P. \& M. W. CALLMANDER. 2010. Phylogeny and circumscription of Sapindaceae revisited: molecular sequence data, morphology and biogeography support recognition of a new family, Xanthoceraceae. Pl. Ecol.Evol. 143: 148-161.

CAO, L. M., N. H. Xia \& Y. F. DENG. 2008. Embryology of Handeliodendron bodinieri (Sapindaceae) and its systematic value: development of male and female gametophytes. Pl. Syst. Evol. 274: 17-23.

CORNER, E. J. H. 1976. Seeds of Dicotyledons, Cambridge University Press, Cambridge.

DAVIS, G. L. 1966. Systematic Embryology of the Angiosperms. Wiley, New York.

ERDTMAN, G. 1960. The acetolysis method. A revised description. Svensk Bot. Tidskr. 54: 561-564.

ERDTMAN, G. 1966. Pollen morphology and plant taxonomy. Angiosperms. New York.

FERRUCCI, M. S. 1991. Sapindaceae. En: R. S. Spichiger \& L. Ramella, Flora del Paraguay. 1-144.

FERRUCCI, M. S. 1998. Sapindaceae. En A. T. Hunziker (ed), Flora Fanerogámica Argentina. 52: 1-44.

GONZALEZ, A. M. \& C. L. CRISTÓBAL. 1997. Anatomía y ontogenia de semillas de Helicteres Lhotzkyana (Sterculiaceae). Bonplandia 9: 287-294.

GULATI, N. \& S. MATHUR. 1977. Embriology and taxonomy of Filicium decipiens. Phytomorphology 27: 261-266.

HA C. O, V. E. SANDS, E. SOEPADMO \& K. JONG. 1988. Reproductive patterns of selected understorey trees in the Malaysian rain forest: the sexual species. Bot. J. Linn. Soc. 97: 295-316.

JOHANSEN, D. A. 1940. Plant Microtechnique. McGraw-Hill Book Co. New York.

JOLY, C. A., FELLIPPE, G. M. \& T. S MELHEM. 1980. Taxonomic studies in Magonia St.-Hil. (Sapindaceae). Brittonia 32: 380-386.

KADRY, A. 1946. Embriology of Cardiospermum halicacabum L. Svensk. Bot. Tidskr. 40: 111-126.

LUQUE, R., H. C. SOUSA \& J. E. KRAUS. 1996. 
Métodos de coloração de Roeser (1972) modificado- E Kropp (1972), visando a substituição do Azul de Astra por Azul de Alcião 8GS ou 8GX. Acta Bot. Bras. 10: 199-212.

MATHUR, S. \& N. GULATI. 1980. Embryology and taxonomy of Allophylus alnifolius Radlk. ex Engl. (Sapindaceae). Indian. J. Bot. 3: 103-112.

MATHUR, S. \& N. GULATI. 1981. Embryology of Lepidopetalum jackianum Hiern. Indian J. Bot. 4: 216-221.

MATHUR, S. \& N. GULATI. 1989. Embryological studies in Allophylus zeylanicus Linn. Indian J. Bot. 12:62-65.

NAIR, N. C. \& J. JOSEPH. 1960. Morphology and embryology of Cardiospermum halicacabum. J. Indian Bot. Soc. 39: 176-194.

PUNT, W., P. P. HOEN, S. BLACKMORE, S. NILSSON $\&$ A. LE THOMAS. 2007. Glossary of pollen and spore terminology. Rev. Paleobot. Palynol. 143: $1-81$.

RADLKOFER, L. 1931-1934. Sapindaceae. En Engler, Pflanzenr. 4: 1-1539.

SHAMROV, I. I. 1998. Ovule classification in flowering plants - New approaches and concepts. Bot. Jahrb. Syst. 120: 377-407.
SOLÍS, S. M., B. GALATI \& M. S. FERRUCCI. 2010. Microsporogenesis and microgametogenesis of Cardiospermum grandiflorum and Urvillea chacoensis (Sapindaceae, Paullinieae). Aust. J. Bot. 58: 597-604.

SOLÍS, S. M. 2011. Estudios morfo-anatómicos $\mathrm{y}$ ontogenéticos en flores de Paullinieae y su significado evolutivo. Tesis Doctoral, Universidad Nacional de Córdoba, Argentina.

WECKERLE, C. S. \& R. RUTISHAUSER. 2005. Gynoecium, fruit and seed structure of Paullinieae (Sapindaceae). Bot. J. Linn. Soc. 147: 159-189.

ZHOU, Q. Y. \& G. S. LIU. 2012. The embryology of Xanthoceras and its phylogenetic implications. $\mathrm{Pl}$. Syst. Evol. 298: 457-468.

ZINI, M. L., G. B. GALATI, S. M. SOLÍS \& M. S. FERRUCCI. 2012. Anther structure and pollen development in Melicoccus lepidopetalus (Sapindaceae): An evolutionary approach to dioecy in the family. Flora 207: 712-720.

Recibido el 25 de septiembre de 2013, aceptado el 18 de diciembre de 2013. 